\title{
A Real-World Rheumatology Registry and Research Consortium: The German RheumaDatenRhePort (RHADAR) Registry
}

Stefan Kleinert ${ }^{1,2}$, MD; Peter Bartz-Bazzanella ${ }^{3}$, MD; Cay von der Decken ${ }^{3,4}$, MD; Johannes Knitza ${ }^{5}$, MD; Torsten Witte $^{6}$, MD; Sándor P Fekete ${ }^{7}$, Prof Dr; Matthias Konitzny ${ }^{7}$, MSc; Alexander Zink ${ }^{8}$, MD, MPH, PhD; Georg Gauler ${ }^{9}$, MD; Patrick Wurth ${ }^{9}$, MD; Peer Aries ${ }^{10}$, MD; Kirsten Karberg ${ }^{11}$, MD; Christoph Kuhn ${ }^{12}$, MD; Florian Schuch ${ }^{1}$, MD; Susanna Späthling-Mestekemper ${ }^{13}$, MD; Wolfgang Vorbrüggen ${ }^{14}$, MD; Matthias Englbrecht ${ }^{15}$, Dr; Martin Welcker ${ }^{16}$, MD; RHADAR Group ${ }^{17}$

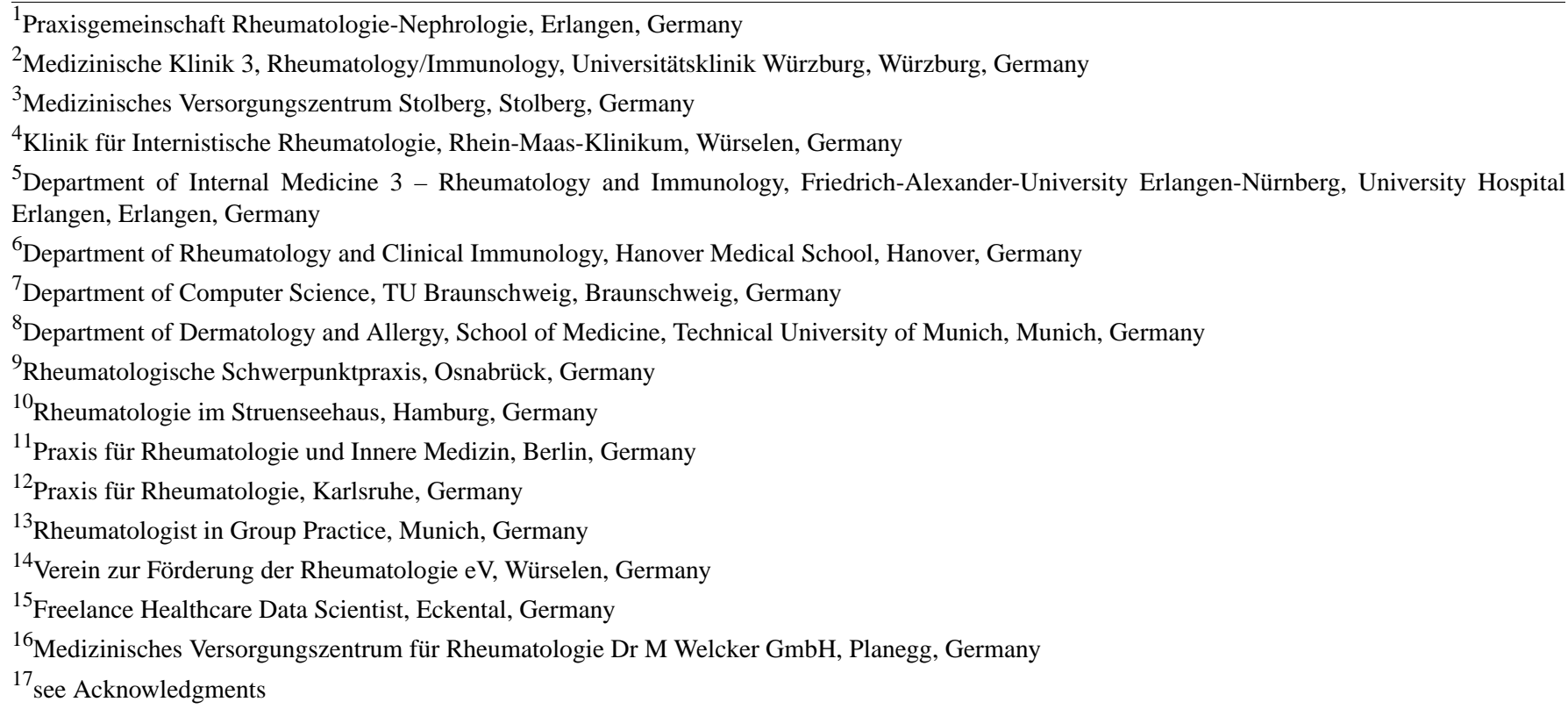

\section{Corresponding Author:}

Stefan Kleinert, MD

Praxisgemeinschaft Rheumatologie-Nephrologie

Möhrendorferstr 1c

Erlangen

Germany

Phone: 499131890031

Fax: 499131890050

Email: stefan.kleinert@pgrn.de

\section{Abstract}

Real-world data are crucial to continuously improve the management of patients with rheumatic and musculoskeletal diseases (RMDs). The German RheumaDatenRhePort (RHADAR) registry encompasses a network of rheumatologists and researchers in Germany providing pseudonymized real-world patient data and allowing timely and continuous improvement in the care of RMD patients. The RHADAR modules allow automated anamnesis and adaptive coordination of appointments regarding individual urgency levels. Further modules focus on the collection and integration of electronic patient-reported outcomes in between consultations. The digital RHADAR modules ultimately allow a patient-centered adaptive approach to integrated medical care starting as early as possible in the disease course. Such a closed-loop system consisting of various modules along the whole patient pathway enables comprehensive and timely patient management in an unprecedented manner.

(J Med Internet Res 2021;23(5):e28164) doi: 10.2196/28164 


\section{KEYWORDS}

registry; rheumatology; real-world data; symptom checker; patient-reported outcomes

\section{Current Challenges in Rheumatology}

The efficacy and safety of treatments for patients with rheumatic and musculoskeletal diseases (RMDs) have continuously improved during previous decades. However, the combination of a declining number of rheumatologists [1] on the one hand and a rising life expectancy in developed countries on the other imposes a significant challenge to rheumatology care nowadays. The growing need for a professional evaluation of common symptoms, such as joint pain [2,3], can hardly be met by the number of available rheumatologists. Besides the lack of the latter, multiple factors contribute to the omnipresent diagnostic delay in rheumatology. Unspecific rheumatic symptoms are challenging to patients [4], general practitioners [5], and experienced rheumatologists [6] alike. Even the most advanced and innovative therapies cannot reverse the health impairment that manifests due to diagnostic delay. "Time is joint" depicts the concept of a timely diagnosis as an indispensable goal in rheumatology. Focusing on this goal could be more cost-effective and generate better outcomes than the development of new RMD drugs.

The shortage of rheumatologists translates to reduced doctor-patient time, especially for follow-up appointments. On average, patients have appointments every 3 to 6 months, while rheumatologists spend 15 minutes for each consultation. In complex diseases like RMDs, the long-term treatment effectiveness cannot be deduced from a single laboratory result like $\mathrm{HbA}_{1 \mathrm{c}}$ in diabetes mellitus. The current monitoring approach in rheumatology relies mainly on the collection of laboratory, clinical, and anamnestic snapshots. This "black box" monitoring approach hardly represents modern personalized medicine. Apart from diagnostic delay, timely treatment adaptions are hampered by the status-quo approach.

Rheumatology encompasses various rare diseases, with limited evidence aiding clinicians in their treatment decisions. Despite the growing number of therapeutic options and treatment guidelines, patients frequently feel like guinea pigs, with prescribed anti-inflammatory treatments not showing the expected therapeutic effect. Thus, clinical evidence supported by real-world data is needed to improve personalized evidence-based treatment decisions.

\section{Potential of a Digital Patient Pathway in Rheumatology}

The potential of digitalization in rheumatology has been depicted in recent publications [7-14]. The European League Against Rheumatism (EULAR) recommends that patients experiencing morning stiffness, joint pain, or swollen joints should see a rheumatologist no later than 6 weeks after symptom onset [15]. A symptom-based, patient-centered, digital screening approach could allow the successful implementation of this guideline. This low burden approach could effectively cut diagnostic delay. The omnipresence of smartphones in the RMD population [14] (irrespective of age) and instinctive digital symptom-based search for solutions $[2,3,11,14]$ represent an immense potential to guide and triage patient streams effectively.

Electronic patient-reported outcomes (ePROs) allow for an individual, continuous, flexible, asynchronous, and need-adapted patient follow-up. Only few rheumatologists are currently using ePROs in clinical routine, mainly due to unawareness of suitable software solutions [13]. Similarly, only few RMD patients are aware of useful rheumatology-specific medical applications [14]. However, rheumatologists and patients are motivated to use ePROs and rheumatology-specific applications in the future $[9,13,14,16]$. A randomized controlled trial could show that an ePROs-based telehealth follow-up strategy can achieve similar disease control as conventional follow-up [17]. This need-adapted follow-up strategy could set precious resources free, which could thus reduce the diagnostic and monitoring delay in RMD patients. A parallel collection of ePROs may facilitate the integration of ePROs into the daily routine. Importantly, wearable-based ePROs produce continuous data sets and can accurately predict disease flares in patients with rheumatoid arthritis and axial spondyloarthritis [18].

Digital registries are crucial for RMD research. Only in a collaborative effort [19] significant amounts of data can be gathered to improve knowledge among rheumatologists. Registries are urgently needed to support RMD patients' management based on evidence. Registries have helped to provide knowledge for rare diseases, such as myositis [20], specific patient scenarios, such as pregnancy [21], and the safety of biologic therapy [22]. Unfortunately, the data collection approach of most patient registries relies on cumbersome active and redundant manual data entry, which frequently lacks precision or completeness [23]. Values can be inconsistent, out of range, or even completely made up. Most importantly, data entry and employment often stop with the end of financial support [24]. Fortunately, most RMD patients are willing to share their data for research purposes [14].

\section{RheumaDatenRhePort Patient Pathway}

The RheumaDatenRhePort (RHADAR) registry (Figure 1) is based on a framework of complementary software modules covering the patient pathway from symptom onset through the disease course. 
Figure 1. RHADAR patient and data pathway. Green boxes resemble established parts of the RHADAR network. Orange boxes are in preparation. RHADAR: RheumaDatenRhePort.

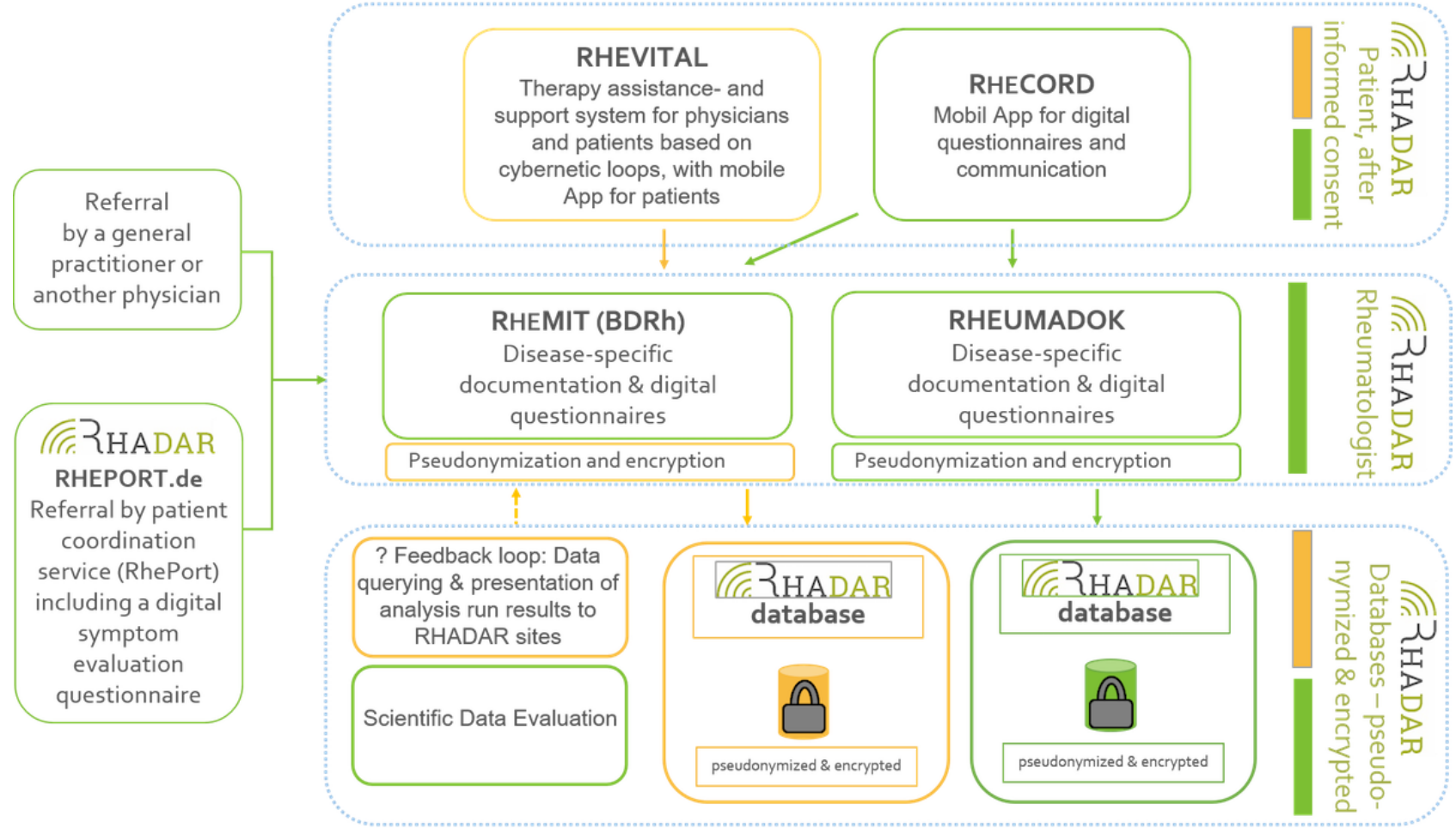

\section{RhePort: Digital Gate to Rheumatology Care}

RHADAR provides low burden direct digital access to a growing network of participating rheumatology sites. The gate module toward RHADAR rheumatology care is RhePort (Figure 2) [25].

Online registration is necessary to use RhePort, and users need to actively consent to the addition of their data to the RHADAR registry.

Figure 2. Screenshots of RhePort.

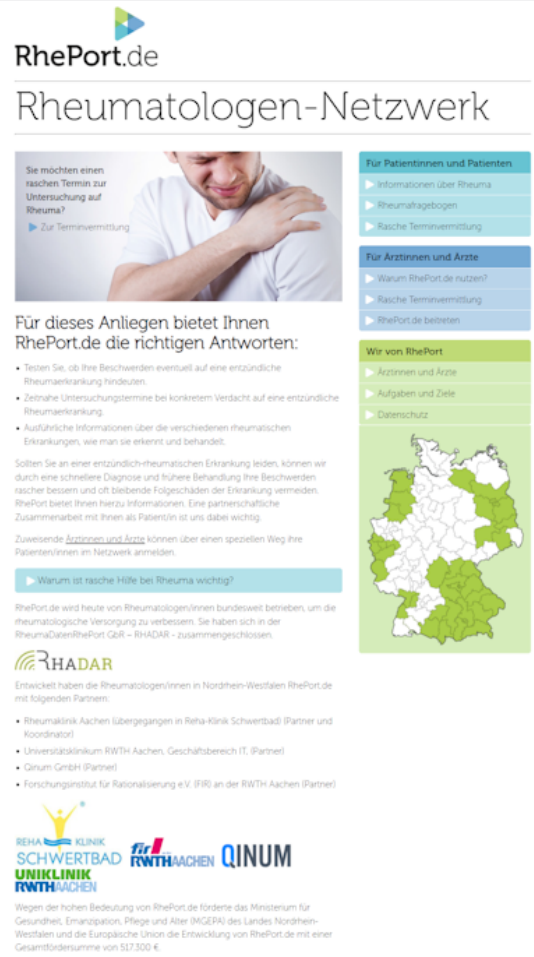

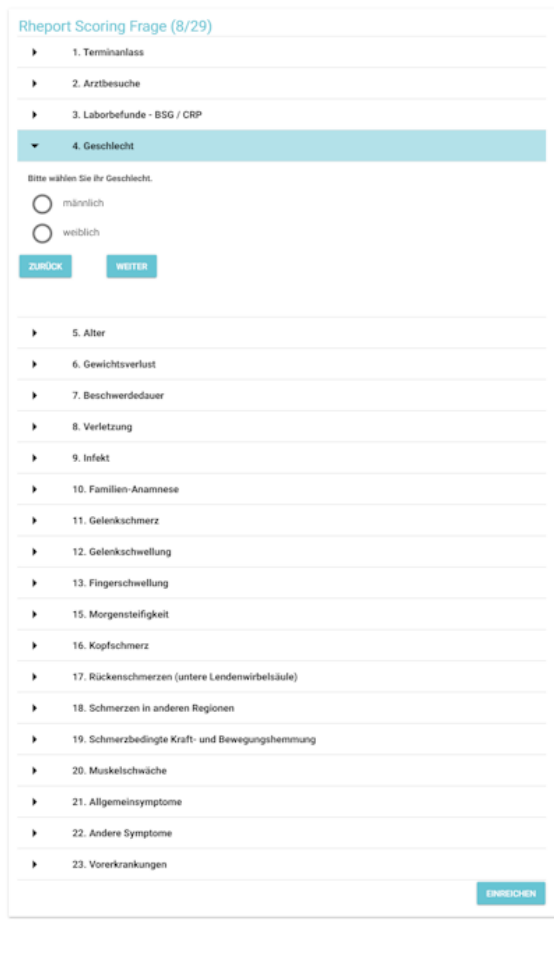

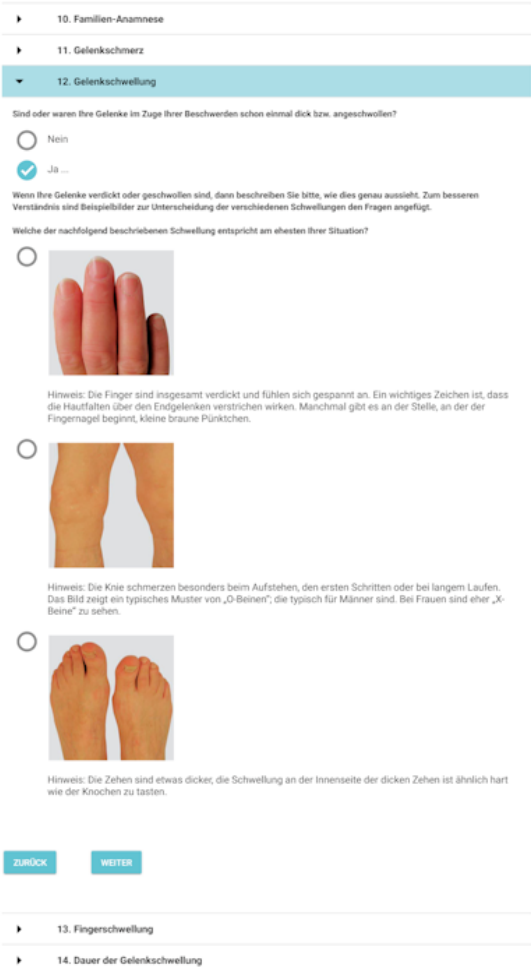

RhePort currently consists of a questionnaire that takes on average 9 minutes to complete [26]. It includes necessary demographic information, current symptoms, and already collected laboratory reports. Based on the patient's answers, RhePort calculates the RMD risk. The implemented algorithm refers to a weighted sum score. Individual weights were derived 
by consensus and the work experience of the RhePort founders. Based on the RhePort RMD risk score, an individual triage level is determined. Currently, there are four triage levels as follows: (1) very urgent, (2) urgent, (3) intermediate, and (4) unlikely. Based on the corresponding level, the patient gets access to locally available RHADAR rheumatology site appointments.

The questionnaire threshold focuses on sensitivity, that is, omitting false-negative ratings. Furthermore, participating rheumatology sites are encouraged to use RhePort only on a complimentary basis. Proft et al recently showed that an online self-referral strategy can successfully be used in addition to the traditional physician-based referral [27]. By including patients based on symptoms, at-risk RMD patients are included in the registry as well. In an interim analysis of a head-to-head randomized controlled trial, the diagnostic accuracy of RhePort was similar to an artificial intelligence-based symptom checker regarding the presence of RMDs [26].

\section{RheCORD: Digital Companion App}

RheCORD (Figure 3) [28] is a rheumatological medical app currently being developed to enable the collection of ePROs. RheCORD gives insights into the patient's symptom state between consultations or before an upcoming appointment on the same day. The ePROs to be collected can individually be determined by the patient [14,29] and local rheumatology site [13] via shared decision-making. The app provides multiple optional secondary features, such as medication and appointment reminders. Feature selection and app development are carried out with respect to guidelines [30,31], app analysis [31], and patient insights [14,29]. RheCORD is based on the previous CE-certified medical apps RheumaLive, AxSpALive, and PsALive. RHADAR sites provide a free soft token and password to the patient via a $\mathrm{QR}$ code to enable encrypted data transfer to the site.

Figure 3. Screenshots of RheCORD.

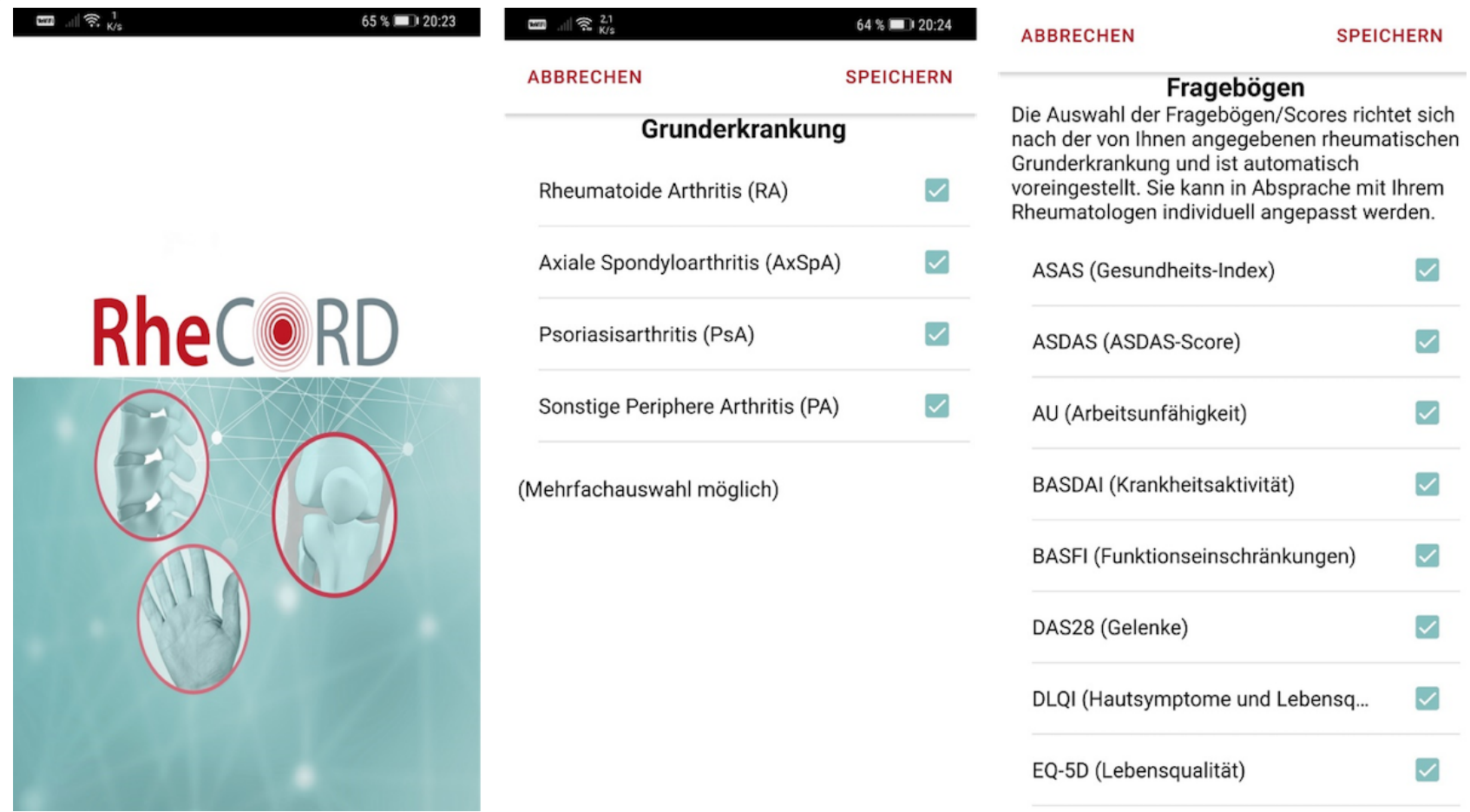

\section{RheumaDok}

RheumaDok (Figure 4) is the current core application used by the RHADAR system for patient data collection. It is a Microsoft Access (Microsoft Corp) database developed in Visual Basic for Applications and is available free of charge for rheumatologists in Germany who are members of the German Rheumatologists' Professional Association (Berufsverband Deutscher Rheumatologen [BDRh]). This database was developed by the Nils Körber und Joachim Elgas GbR. In the months ahead, RheumaDok will be replaced by RheMIT. 
Figure 4. Screenshot of RheumaDok.

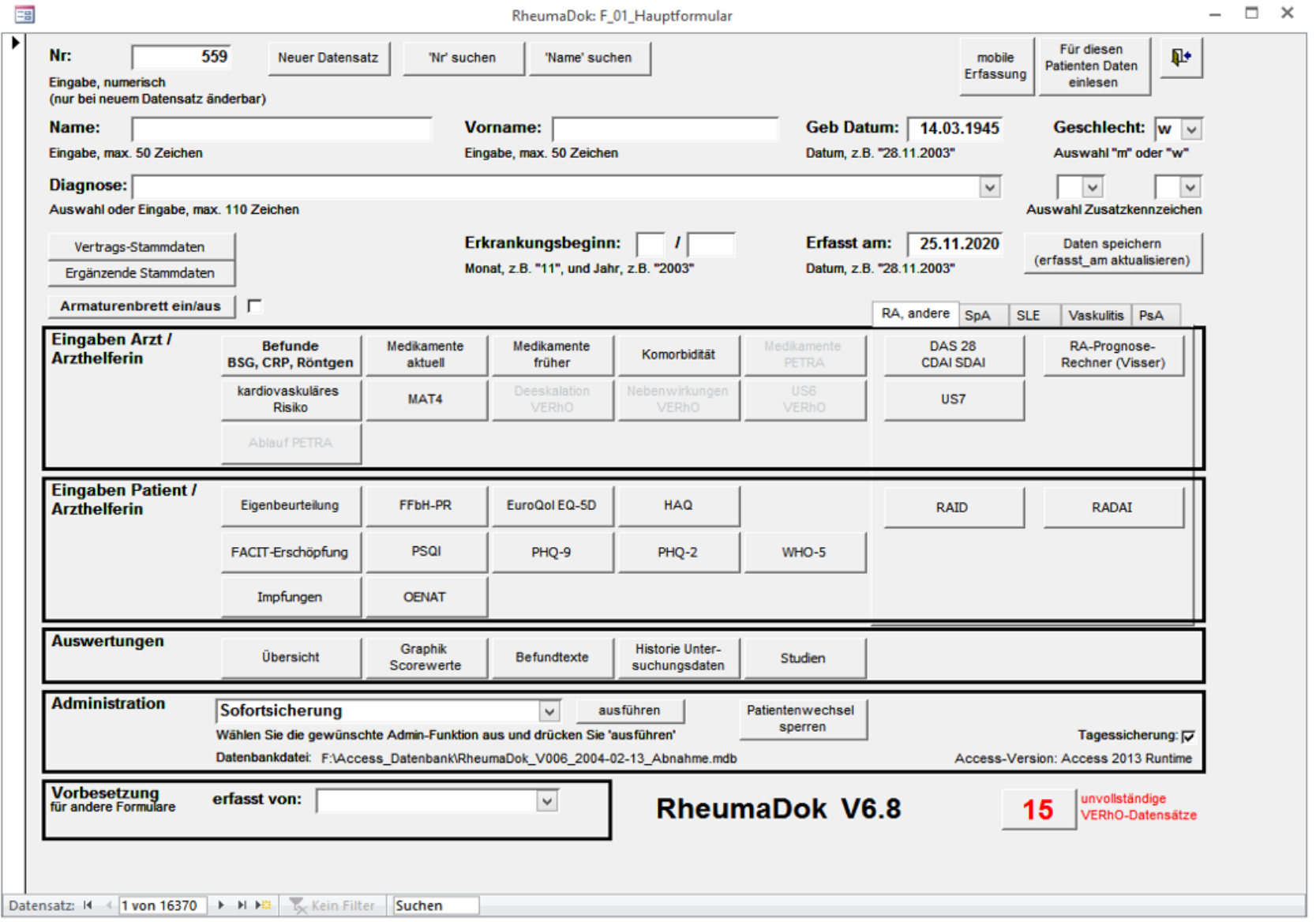

\section{RheMIT: Clinical Documentation Software}

RheMIT (Figure 5) is currently becoming the standard clinical documentation software for rheumatologists in Germany. The software has been developed and adapted by itc-ms.de for the German Rheumatologists' Professional Association (BDRh) [7]. The software offers standardized entry masks to document the patient's disease course at each consultation, including standard disease activity measures, general or disease-specific PROs, demographic characteristics, comorbidities, and current as well as previous antirheumatic treatments. If patients provide their consent, pseudonymized information will be uploaded to the RHADAR registry. 
Figure 5. Screenshot of RheMIT.

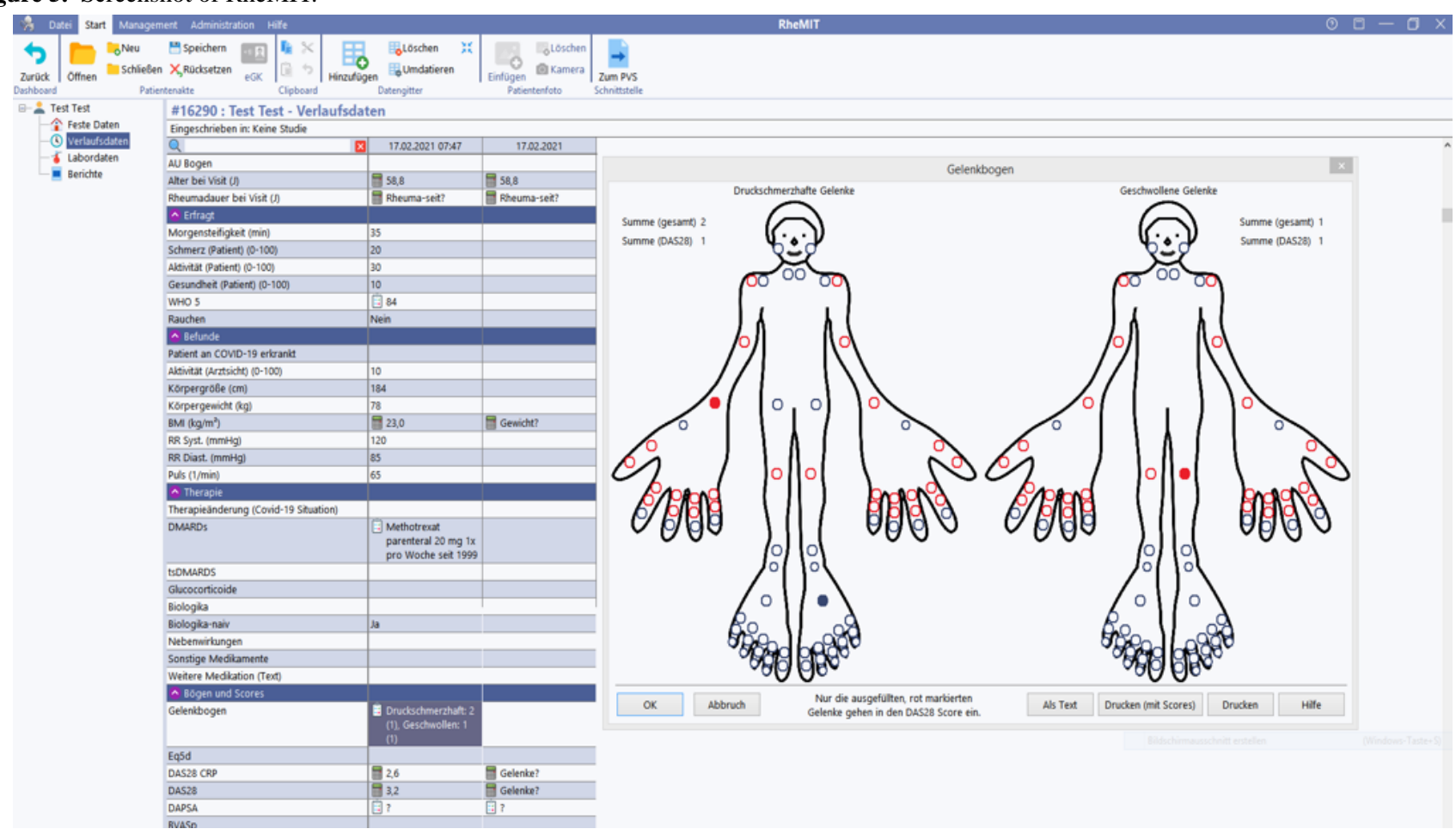

\section{RHADAR Registry}

All information from RheCORD and local RheumaDok database instances are pseudonymized at each participating site. Subsequently, data are merged in a mutual database. The responsible data protection authority approved the current RHADAR database environment to ensure data privacy according to legislation. Patients participating in the RHADAR network have to complete an informed consent form before their initial data entry. Participation is voluntary for each patient. Participants and patients refusing to participate are treated equally, following national guidelines and rheumatologic care standards in Germany. As of September 2020, 22 rheumatologists at eight sites provided data to the RHADAR registry, including a total of 15,908 patients.

\section{RHADAR Outlook}

RHADAR software modules are continuously being improved based on new technological standards, user preferences, and scientific literature. For instance, a machine-learning approach to improve the triage performance of the RhePort algorithm is being evaluated based on current data. The implementation of an objective, standardized, and evidence-based triage algorithm seems crucial. Additionally, a complementary software module, RheVITAL [32], is under development in cooperation with the largest German patient organization, the German Rheumatism League ("Deutsche Rheuma-Liga"), to facilitate RMD disease management. Several registry analyses are being carried out and are set to directly impact future RMD management. A new database is currently under construction, and it will include data from all current and future software modules. Growing awareness of the integrative RHADAR system and its distribution will foster networking of rheumatology sites.

\section{Acknowledgments}

The authors thank all patients, partners, and collaborators for their support of the RHADAR registry. The authors would especially like to thank Monika Ronneberger, Praxedis Rapp, Jörg Wendler, Sonja Baltrusch, Florian Popp, Patrizia Sternad, Alexandra Edhofer, Ernestina Guillen Poveda, Yella C Rottländer, Sybille Kramer, Benjamin Schulte, Ramona Merkle, and Dorthe Gruber for their support in the data acquisition process and during data completion. The authors would like to thank Nils Körber, the developer of the initial RHADAR database, for his support and consultation during the project roll out; Michael Schumann, the developer of the successor RHADAR database, for his support and cooperation; and Achim Fricker, the cooperation partner developing RhePort with the founders, for his support. This study was funded by the RheumaDatenRhePort GbR, Bahnhofstr. 32, 82152 Planegg, Germany.

The members of the RHADAR Group, Planegg, Germany includes Monika Ronneberger, Praxedis Rapp, Jörg Wendler, Sonja Baltrusch, Florian Popp, Patrizia Sternad, Alexandra Edhofer, Ernestina Guillen Poveda, Yella C Rottländer, Sybille Kramer, Benjamin Schulte, Ramona Merkle, Dorthe Gruber, Nils Körber, and Achim Fricker. 


\section{Authors' Contributions}

All authors wrote, reviewed, and approved the final manuscript.

\section{Conflicts of Interest}

WV, CD, SK, PB-B, and MW are members of RheumaDatenRhePort. WV, CD, and PB-B were involved in the development of Rheport. JK, AZ, TW, and SPF are members of the scientific board of RheumaDatenRhePort.

RhePort was developed and provided by the Verein zur Förderung der Rheumatologie eV, Würselen, Germany, and QINUM $\mathrm{GmbH}$, Cologne, Germany. The development was supported by the government of Northrhine-Westfalia, Germany, and by the European Union (EFRE; AZ: 005-GW02-075A). The maintenance of this service has been supported by AbbVie, Novartis, Chugai, UCB, and Sanofi-Aventis. RheVITAL was developed and provided by the Verein zur Förderung der Rheumatologie eV, Würselen, Germany; QINUM GmbH, Cologne, Germany; and the Martin-Luther- Universität Halle, Halle, Germany. The development was supported by the government of Northrhine-Westfalia, Germany, and by the European Union (EFRE; Förderkennzeichen: EFRE-0800750). RheumaDok and the RHADAR database were developed and technically implemented by Nils Körber and Joachim Elgas GbR, Erlangen, Germany. RheMIT has been developed for the German Rheumatologists' Professional Association (Berufsverband Deutscher Rheumatologen) by itc-ms.de, Marburg, Germany. The app RheCORD is the property of the RheCordHealthCare GmbH. It was preceded by AxSpALive, PsALive, and RheumaLive. The latter three were sponsored by UCB Pharma GmbH, Monheim, Germany. All apps were developed and technically implemented by Star Healthcare Management GmbH, Cologne, Germany. JK has received research support from Novartis Pharma GmbH to evaluate RhePort.

GG receives speaker and consulting fees from Abbvie, Celgene, Chugai, Gilead, Novartis, and UCB. CK, KK, and SS-M are members of RheumaDatenRhePort GbR that had part of the software developed as described in this publication. FS is part of the advisory board at Abbvie, Gilead, Novartis, and Sanofi Aventis. ME has received remunerations from RheumaDatenRhePort GbR for statistical data analyses \& consultation.

The RHADAR GbR has received honoraria from UCB Pharma GmbH, Sandoz Deutschland/Hexal AG, and Lilly GmbH, and research support from Novartis Pharma GmbH.

\section{References}

1. Krusche M, Sewerin P, Kleyer A, Mucke J, Vossen D, Morf H, Rheumadocs und Arbeitskreis Junge Rheumatologie (AGJR). Facharztweiterbildung quo vadis? Specialist training quo vadis? Z Rheumatol 2019 Oct;78(8):692-697. [doi: 10.1007/s00393-019-00690-5] [Medline: 31468164]

2. Dey M, Zhao SS. Google search data as a novel adjunct to patient and public involvement in rheumatology research. Rheumatol Int 2021 Apr 19;41(4):771-779 [FREE Full text] [doi: 10.1007/s00296-020-04723-0] [Medline: 33074346$]$

3. Kardeş S, Kuzu AS, Raiker R, Pakhchanian H, Karagülle M. Public interest in rheumatic diseases and rheumatologist in the United States during the COVID-19 pandemic: evidence from Google Trends. Rheumatol Int 2021 Feb;41(2):329-334 [FREE Full text] [doi: 10.1007/s00296-020-04728-9] [Medline: 33070255]

4. Raciborski F, Kłak A, Kwiatkowska B, Batko B, Sochocka-Bykowska M, Zoń-Giebel A, working team. Diagnostic delays in rheumatic diseases with associated arthritis. Reumatologia 2017;55(4):169-176 [FREE Full text] [doi:

10.5114/reum.2017.69777] [Medline: 29056771]

5. van der Linden MPM, le Cessie S, Raza K, van der Woude D, Knevel R, Huizinga TWJ, et al. Long-term impact of delay in assessment of patients with early arthritis. Arthritis Rheum 2010 Dec 30;62(12):3537-3546 [FREE Full text] [doi: 10.1002/art.27692] [Medline: 20722031]

6. Ehrenstein B, Pongratz G, Fleck M, Hartung W. The ability of rheumatologists blinded to prior workup to diagnose rheumatoid arthritis only by clinical assessment: a cross-sectional study. Rheumatology (Oxford) 2018 Sep 01;57(9):1592-1601. [doi: 10.1093/rheumatology/key127] [Medline: 29850885]

7. Fiehn C, Baraliakos X, Edelmann E, Froschauer S, Feist E, Karberg K, et al. [Current state, goals and quality standards of outpatient care in rheumatology: position paper of the Professional Association of German Rheumatologists (BDRh)]. Z Rheumatol 2020 Oct;79(8):770-779. [doi: 10.1007/s00393-020-00872-6] [Medline: 32926218]

8. Knitza J, Callhoff J, Chehab G, Hueber A, Kiltz U, Kleyer A, et al. [Position paper of the commission on digital rheumatology of the German Society of Rheumatology: tasks, targets and perspectives for a modern rheumatology]. Z Rheumatol 2020 Aug;79(6):562-569. [doi: 10.1007/s00393-020-00834-y] [Medline: 32651681]

9. Kernder A, Morf H, Klemm P, Vossen D, Haase I, Mucke J, et al. Digital rheumatology in the era of COVID-19: results of a national patient and physician survey. RMD Open 2021 Feb;7(1) [FREE Full text] [doi: 10.1136/rmdopen-2020-001548] [Medline: $\underline{33622673}$ ]

10. Knitza J, Knevel R, Raza K, Bruce T, Eimer E, Gehring I, JPAST Group. Toward Earlier Diagnosis Using Combined eHealth Tools in Rheumatology: The Joint Pain Assessment Scoring Tool (JPAST) Project. JMIR Mhealth Uhealth 2020 May 15;8(5):e17507 [FREE Full text] [doi: 10.2196/17507] [Medline: $\underline{\text { 32348258] }}$ 
11. Powley L, McIlroy G, Simons G, Raza K. Are online symptoms checkers useful for patients with inflammatory arthritis? BMC Musculoskelet Disord 2016 Aug 24;17(1):362 [FREE Full text] [doi: 10.1186/s12891-016-1189-2] [Medline: $\underline{27553253]}$

12. Hirsch MC, Ronicke S, Krusche M, Wagner AD. Rare diseases 2030: how augmented AI will support diagnosis and treatment of rare diseases in the future. Ann Rheum Dis 2020 Jun;79(6):740-743 [FREE Full text] [doi:

10.1136/annrheumdis-2020-217125] [Medline: 32209541]

13. Krusche M, Klemm P, Grahammer M, Mucke J, Vossen D, Kleyer A, et al. Acceptance, Usage, and Barriers of Electronic Patient-Reported Outcomes Among German Rheumatologists: Survey Study. JMIR Mhealth Uhealth 2020 Jul 20;8(7):e18117 [FREE Full text] [doi: 10.2196/18117] [Medline: 32390592]

14. Knitza J, Simon D, Lambrecht A, Raab C, Tascilar K, Hagen M, et al. Mobile Health Usage, Preferences, Barriers, and eHealth Literacy in Rheumatology: Patient Survey Study. JMIR Mhealth Uhealth 2020 Aug 12;8(8):e19661 [FREE Full text] [doi: 10.2196/19661] [Medline: $\underline{\text { 32678796] }}$

15. Combe B, Landewe R, Daien CI, Hua C, Aletaha D, Álvaro-Gracia JM, et al. 2016 update of the EULAR recommendations for the management of early arthritis. Ann Rheum Dis 2017 Jun;76(6):948-959. [doi: 10.1136/annrheumdis-2016-210602] [Medline: 27979873]

16. Knitza J, Vossen D, Geffken I, Krusche M, Meyer M, Sewerin P, Arbeitskreis Junge Rheumatologen. [Use of medical apps and online platforms among German rheumatologists : Results of the 2016 and 2018 DGRh conference surveys and research conducted by rheumadocs]. Zeitschrift für Rheumatologie 2019;78:839-846. [doi: 10.1007/s00393-018-0578-3] [Medline: 30542914]

17. de Thurah A, Stengaard-Pedersen K, Axelsen M, Fredberg U, Schougaard LMV, Hjollund NHI, et al. Tele-Health Followup Strategy for Tight Control of Disease Activity in Rheumatoid Arthritis: Results of a Randomized Controlled Trial. Arthritis Care Res (Hoboken) 2018 Mar 23;70(3):353-360 [FREE Full text] [doi: 10.1002/acr.23280] [Medline: 28511288]

18. Gossec L, Guyard F, Leroy D, Lafargue T, Seiler M, Jacquemin C, et al. Detection of Flares by Decrease in Physical Activity, Collected Using Wearable Activity Trackers in Rheumatoid Arthritis or Axial Spondyloarthritis: An Application of Machine Learning Analyses in Rheumatology. Arthritis Care Res (Hoboken) 2019 Oct;71(10):1336-1343. [doi: 10.1002/acr.23768] [Medline: 30242992]

19. Krusche M, Burmester GR, Knitza J. Digital crowdsourcing: unleashing its power in rheumatology. Ann Rheum Dis 2020 Sep;79(9):1139-1140 [FREE Full text] [doi: 10.1136/annrheumdis-2020-217697] [Medline: 32527863]

20. Lilleker JB, Vencovsky J, Wang G, Wedderburn LR, Diederichsen LP, Schmidt J, et al. The EuroMyositis registry: an international collaborative tool to facilitate myositis research. Ann Rheum Dis 2018 Jan;77(1):30-39 [FREE Full text] [doi: 10.1136/annrheumdis-2017-211868] [Medline: 28855174]

21. Müller-Ladner U, Fischer-Betz R. German Pregnancy Register "Rhekiss". Dtsch Arztebl Int 2018 Feb 16;115(7):112 [FREE Full text] [doi: 10.3238/arztebl.2018.0112a] [Medline: 29510821]

22. Strangfeld A, Zink A. Sicherheit unter Biologika - Ergebnisse aus dem deutschen Biologika-Register RABBIT [Safety of biologic therapy - results from the German biologics register RABBIT]. Dtsch Med Wochenschr 2014 Sep;139(37):1817-1820. [doi: 10.1055/s-0034-1370252] [Medline: 25180996]

23. Managing Missing Data in Patient Registries. Agency for Healthcare Research and Quality. 2018. URL: https:/ leffectivehealthcare.ahrq.gov/products/registries-guide-4th-edition/white-paper-2016-2 [accessed 2021-05-17]

24. Garrison HH, Deschamps AM. NIH research funding and early career physician scientists: continuing challenges in the 21st century. FASEB J 2014 Mar;28(3):1049-1058 [FREE Full text] [doi: 10.1096/fj.13-241687] [Medline: 24297696]

25. RhePort. URL: www.rheport.de [accessed 2021-05-13]

26. Knitza J, Mohn J, Bergmann C, Kampylafka E, Hagen M, Bohr D, et al. Ab1346-Hpr Real-World Effectiveness and Perceived Usefulness of Symptom Checkers in Rheumatology: Interim Report from the Prospective Multicenter Better Study. Ann Rheum Dis 2020 Jun 02;79(Suppl 1):1961. [doi: 10.1136/annrheumdis-2020-eular.1604]

27. Proft F, Spiller L, Redeker I, Protopopov M, Rodriguez VR, Muche B, et al. Comparison of an online self-referral tool with a physician-based referral strategy for early recognition of patients with a high probability of axial spa. Semin Arthritis Rheum 2020 Oct;50(5):1015-1021. [doi: 10.1016/j.semarthrit.2020.07.018] [Medline: $\underline{32911279]}$

28. RheCORD. URL: www.rhecord.de [accessed 2021-05-13]

29. Nowell WB, Gavigan K, Kannowski CL, Cai Z, Hunter T, Venkatachalam S, et al. Which patient-reported outcomes do rheumatology patients find important to track digitally? A real-world longitudinal study in ArthritisPower. Arthritis Res Ther 2021 Feb 10;23(1):53 [FREE Full text] [doi: 10.1186/s13075-021-02430-0] [Medline: 33568191]

30. Najm A, Nikiphorou E, Kostine M, Richez C, Pauling JD, Finckh A, et al. EULAR points to consider for the development, evaluation and implementation of mobile health applications aiding self-management in people living with rheumatic and musculoskeletal diseases. RMD Open 2019;5(2):e001014 [FREE Full text] [doi: 10.1136/rmdopen-2019-001014] [Medline: 31565245]

31. Knitza J, Tascilar K, Messner E, Meyer M, Vossen D, Pulla A, et al. German Mobile Apps in Rheumatology: Review and Analysis Using the Mobile Application Rating Scale (MARS). JMIR Mhealth Uhealth 2019 Aug 05;7(8):e14991 [FREE Full text] [doi: 10.2196/14991] [Medline: 31381501]

32. RheVITAL. URL: www.rhevital.de [accessed 2021-05-13] 


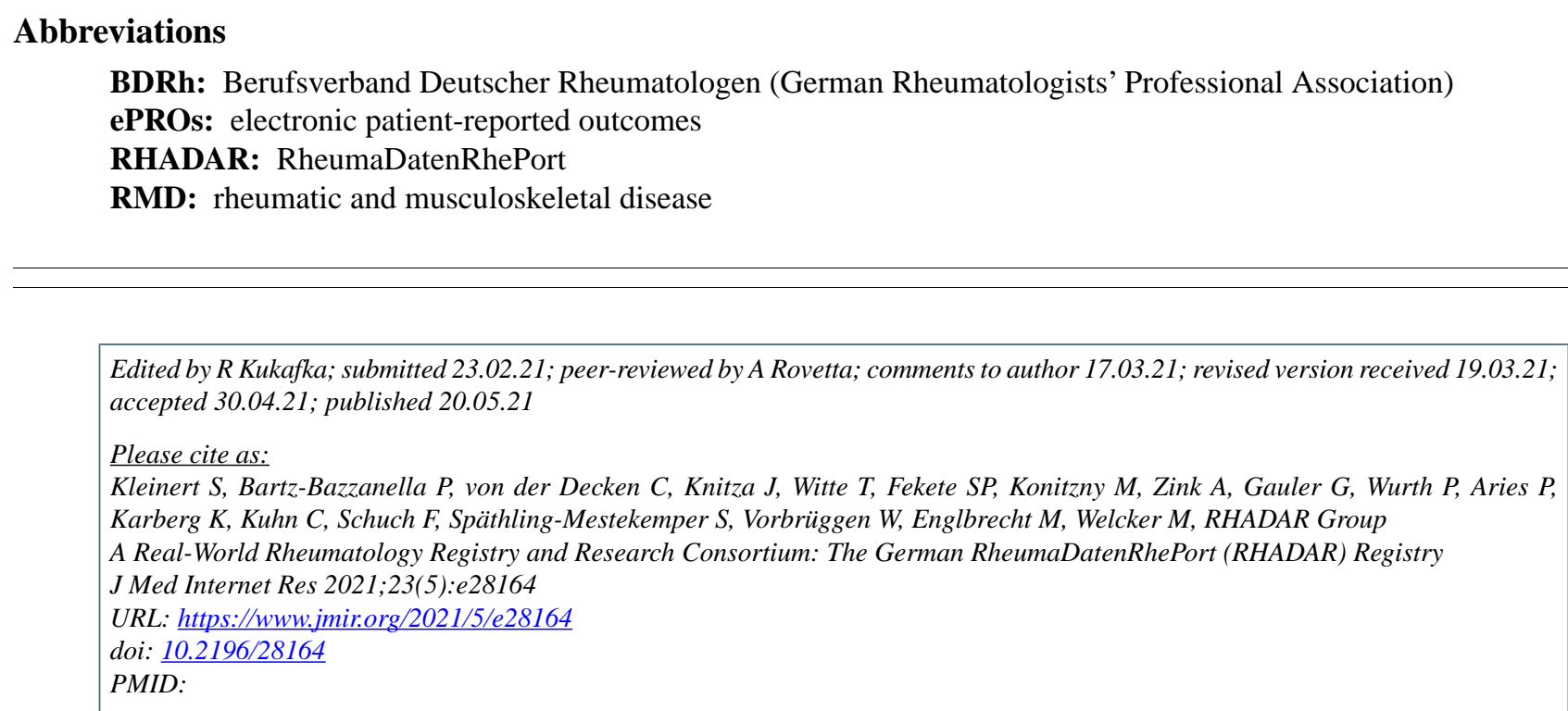

CStefan Kleinert, Peter Bartz-Bazzanella, Cay von der Decken, Johannes Knitza, Torsten Witte, Sándor P Fekete, Matthias Konitzny, Alexander Zink, Georg Gauler, Patrick Wurth, Peer Aries, Kirsten Karberg, Christoph Kuhn, Florian Schuch, Susanna Späthling-Mestekemper, Wolfgang Vorbrüggen, Matthias Englbrecht, Martin Welcker, RHADAR Group. Originally published in the Journal of Medical Internet Research (https://www.jmir.org), 20.05.2021. This is an open-access article distributed under the terms of the Creative Commons Attribution License (https://creativecommons.org/licenses/by/4.0/), which permits unrestricted use, distribution, and reproduction in any medium, provided the original work, first published in the Journal of Medical Internet Research, is properly cited. The complete bibliographic information, a link to the original publication on https://www.jmir.org/, as well as this copyright and license information must be included. 